\title{
Use of Geoinformation and Neurotechnology to Assess and to Forecast the Humus Content Variations in the Steppe Soils
}

\author{
F. N. Lisetskii ${ }^{a, *}$, V. I. Pichura ${ }^{b, * *}$, and D. S. Breus ${ }^{b}$ \\ Presented by Corresponding Member of the Russian Academy of Sciences G. N. Cherkasov \\ ${ }^{a}$ Belgorod National Research University, Belgorod, Belgorod oblast, 308015 Russia \\ ${ }^{b}$ Kherson State Agricultural University, Kherson, Kherson oblast, 73000 Ukraine \\ *e-mail: liset@bsu.edu.ru \\ **e-mail:pichura@yandex.ua \\ Received September 5, 2016
}

\begin{abstract}
This paper reports the results obtained using the systemic basin approach, geoinformation, and neurotechnology for modeling and forecasting of the humus spatial inhomogeneity and content variations in the steppe and dry steppe zones (Kherson oblast, Ukraine). The general trend of such variations has been determined in the $0-40 \mathrm{~cm}$ layer for 42 years. The intensive use of irrigation and drainage activities in 19701989 resulted in a significant humus depletion by $0.36 \%$ on average (from $2.56 \%$ to $2.2 \%$ ). The analysis in 4450 observation points has yielded a decrease in the variability, the rising polynomial dependence of the humus enrichment from the west to the east, and the logarithmic dependence from the south to the north. The neurotechnological modeling has made it possible to develop the artificial neural network for the spatiotemporal modeling of the humus content in the soils. The humus is predicted to be subject to the irreversible process of gradual depletion in the 0-40 layer until 2025 upon the use of the existing agrotechnologies: rainfed land by $0.01 \% /$ year and irrigated land by $0.03 \% /$ year. This result defines the territorial priorities of the regional policy and suggests the differentiated efficiency evaluation of the soil-protective unit of the farming systems.
\end{abstract}

Keywords: soil fertility, humus, modeling, forecasting, multivariate statistics, GIS technologies, neurotechnologies

DOI: $10.3103 / \mathrm{S} 1068367417020112$

\section{INTRODUCTION}

When assessing the quality of agricultural landscapes, the spatiotemporal impact of the agroclimatic conditions and farming culture on the state and changes of soil fertility resources commonly affects the agrochemical condition of the cultivated soils. The analysis of changes in the agrochemical parameters in space and time can be regarded as one of the most important and objective procedures for estimation of the farming system efficiency [1]. The nutrient reserves and availability to the plants, as well as the productive water reserves, are closely related to the natural climatic conditions of the agricultural landscapes (topographic features, soil-forming rocks, climate, hydrogeology, etc.) and the applied farming system, affecting the amount and quality of the agricultural harvests [2-5]. The agrochemical indexes are characterized by great spatial-distribution nonuniformity even within the soil differences as a result of the natural specific features and the practical land use [6].

The investigation objective is to study the spatial distribution nonuniformity of the humus and varia- tions in its content in the Kherson oblast soils for 42 years.

\section{RESEARCH METHODS}

The results of nine five-year investigation tours have served as the modeling information basis: from II (1970-1974) to X (2008-2012). The data from 296 stations of the Oblgosplodorodie Kherson Center (tour X) have been taken into account to estimate the humus content in the cultivated lands. The humus content variations in 2025 have been predicted using the 1978-2014 observation data obtained in 25 stations located within seven natural farming zones. The total humus content in the $0-40 \mathrm{~cm}$ soil layer has been determined by Tyurin's method.

The basin zoning of the Kherson Region has been implemented using the relief digital model developed on the basis of radar mapping. The automated basin zoning was previously considered in [7,8].

The humus content variations in space and time have been predicted using the artificial neural networks and the multilayered perceptron architecture 
[9]. The Statistics Neural Networks (SNN) module has been used to develop the neuromodel of the threelayer perceptron architecture with thirteen neurons in the hidden layer. The training method was inverse distribution (100 periods) and the associated gradients (355 periods); the artificial neural network matrix consisted of 2275 weight coefficients.

Cross checking of the forecast models has been carried out using the statistical criteria of reliability assessment [10]. The radial basis function of the Geostatistical Analyst module has been used in the spatial modeling of the humus nonuniform distribution. The data have been processed with the help of the licensed software: Statistica Advanced + QC for Windows v. 10 $\mathrm{Ru}$, Statistica Automated Neural Networks for Windows v.10 Ru, and ArcGis 10.1.

\section{RESULTS AND DISCUSSION}

Agricultural lands occupy $69 \%$ of the total area of Kherson oblast (1971000 ha), and their structure is dominated by cultivated land (1777600 ha or $90.2 \%)$. Twenty percent of the Ukrainian irrigated lands is concentrated in this region, reaching 426800 ha at 285000 ha factually used. In the regions with the developed irrigation reclamation, the general hydrofunctioning of the basin agroland spatiotemporal system [11] is related to the natural and anthropogenic features of heat and water distribution. The region is located within three types of catchment basins: river basins, 1241300 ha $(35.8 \%)$; cycled up-ground flow basins, 588300 ha (20.7\%); and coastal basins (Black Sea and Sea of Azov), 1016500 ha (35.6\%).

The humus is known to be one of the major resources of the potential soil fertility and the integral indicator of the agrotechnological unit of the farming system. The Kherson soil cover is dominated by lowhumus soils (from 0.30 to $3.85 \%$ ). The main humus soils include the southern black earth occupying $43.7 \%$ of a total area of the agricultural lands and dark brown soils (30.7\%). The common and southern black earths $(67.7 \%)$ are predominant within the river basin; the dark brown and chestnut alkali soils are predominant in the coastal basin (71\%); and the southern black soils occupy $80 \%$ of the cycled up-ground flow basin.

Specific features of the soil cover control the initial humus content undergoing the dynamic changes due to the economic activity; the changes are related to the farming intensity and culture within the land plots (crop rotation fields) and the land use. Under irrigation of different soil types in the Kherson oblast, the humus content is lower by $0.1-0.5 \%$, on average, in the 0-40 layer than in the rainfed lands due to the intensity and technological features of the irrigation reclamations (water quality, irrigation rate, crop rotation, etc.).
The intensive irrigation period started at the time of the tour II and resulted in the considerable humus depletion: by $0.36 \%$ (from 2.56 to $2.20 \%$ ), on average, in 1970-1989. The substantial reduction in the soil humus content and the great spatial nonuniformity of this parameter have been noted in the coastal basin, where more than $59.3 \%$ of the irrigated land (253200 ha) is concentrated. A stable irrigation reclamation loading with an insignificant negative trend of the humus content variations in time $(t)$ marked 1985-2012:

$$
\left(T=-0.0061 t+2.2914 ; R^{2}=0.022\right) .
$$

We have developed the spatial model $\left(R^{2}=0.98\right)$ of humus distribution in the soil cover of the basic Kherson basins using the data from 296 stations for the tour $\mathrm{X}$ monitoring investigations and geostatistical analyses (Fig. 1). Graphic and statistical characteristics of the humus spatial distribution nonuniformity (Fig. 2) have been studied based on this model using the data obtained in 4450 points in the Kherson oblast. These arrangements have made it possible to improve the quality of the spatial information interpretation and the modeling results.

The variability of soil properties throughout the studied area is characterized by the nonstationary (atypical) nature of their distribution in the agricultural landscapes at different observation levels, which is largely due to the soil diversity and agroeconomic differences. In this case, the use of the autocorrelation approach makes it possible to define the maximum distribution distance and to retain the possible spatial energy of the process stationarity (uniformity). This approach can also be used to substantiate the synchronous nature of temporal variations in the studied parameters within the stationarity lag radius. The autocorrelation investigation of the spatial uniformity of the humus content in the soil has been carried out in the direction of increasing the spatial trend from the southwest of the Kherson oblast (the first lag is a reference point) to the northeast. The spatial distance between lags has been $2.5 \mathrm{~km}$. The correlation in the first lag has appeared to be high (0.998), but it decreased in the second lag $(0.015)$ due to the considerable spatial humus distribution nonuniformity. The difference of the first lag has been used to decrease the strength upon retaining the main signal of the nonstationary process. The data conversion yielded the minimum $(r=0.391)$ and the maximum $(r=0.143)$ radius of the humus formation uniformity, which is 2.5 (lag 1$)$ and $12.5 \mathrm{~km}$ (lag 5). The low strength of relationships between the lags is indicative of a significant spatial variability (nonuniformity) of the humus distribution within both the studied basins and the contours of various soil types (subtypes).

The spatial function of humus distribution in the main basins of the Kherson oblast is as follows:

$$
\begin{gathered}
f(h)=25.14 x-11.98 y+0.07 x^{2}-0.63 x y+0.36 y^{2} \\
-168.97 ; R=0.58,
\end{gathered}
$$




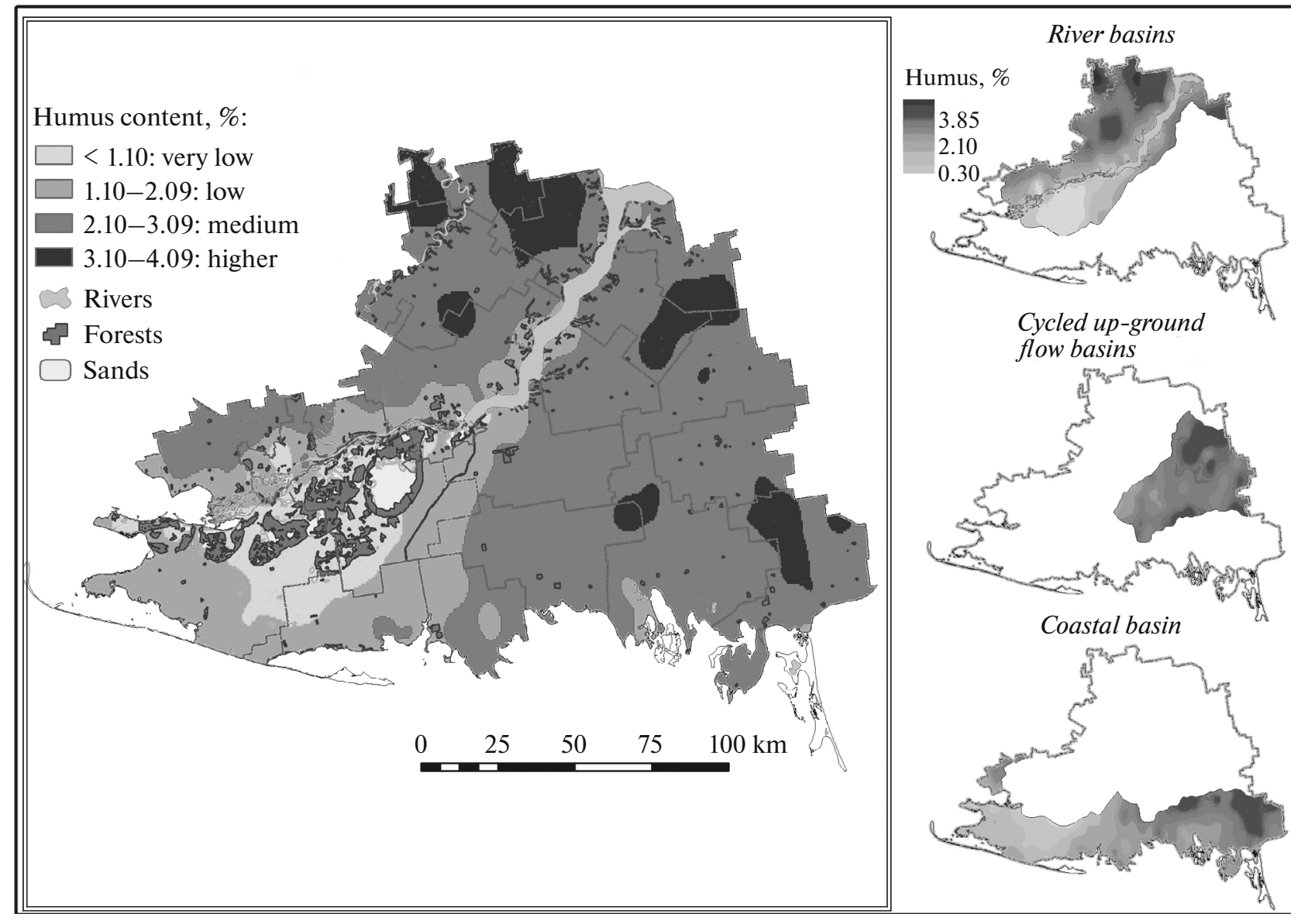

Fig. 1. Humus content distribution in the Kherson oblast soils and within local basins.

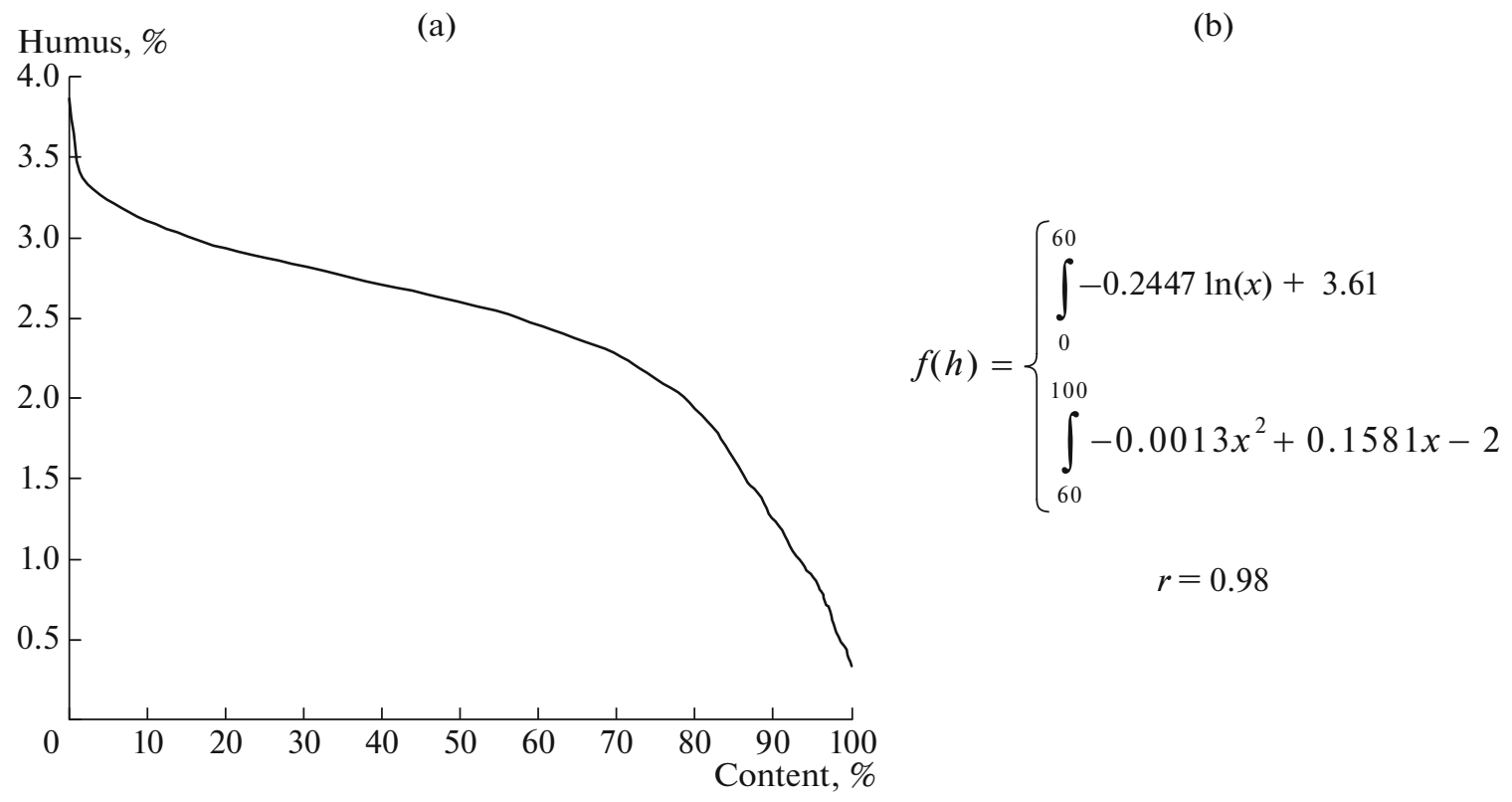

Fig. 2. Model of humus content in the Kherson oblast soils: $(a)$ humus content curve and $(b)$ function. 
Humus content distribution in the soils of agricultural lands and Kherson oblast basins

\begin{tabular}{|c|c|c|c|c|c|c|c|c|c|}
\hline \multirow{3}{*}{\multicolumn{2}{|c|}{ Humus content, $\%$}} & \multicolumn{6}{|c|}{ Basin } & \multirow{2}{*}{\multicolumn{2}{|c|}{ Total }} \\
\hline & & \multicolumn{2}{|c|}{ river basin } & \multicolumn{2}{|c|}{$\begin{array}{l}\text { cycled up-ground } \\
\text { flow basin }\end{array}$} & \multicolumn{2}{|c|}{ coastal basin } & & \\
\hline & & thousand ha & $\%$ & thousand ha & $\%$ & thousand ha & $\%$ & thousand ha & $\%$ \\
\hline Very low & $<1.10$ & 69.4 & 9.1 & - & - & 55.0 & 7.4 & 124.4 & 6.3 \\
\hline Low & $1.10-2.09$ & 171.5 & 22.5 & 6.5072 & 1.4 & 240.3 & 32.3 & 418.3 & 21.2 \\
\hline Medium & $2.10-3.09$ & 362.1 & 47.5 & 415.531 & 89.4 & 404.7 & 54.4 & 1182.3 & 60.0 \\
\hline Higher & $3.10-4.09$ & 159.3 & 20.9 & 42.7616 & 9.2 & 43.9 & 5.9 & 246.0 & 12.5 \\
\hline \multicolumn{2}{|l|}{ Total } & 762.3 & 100 & 464.8 & 100 & 743.9 & 100 & 1971.0 & 100 \\
\hline
\end{tabular}

where $x$ and $y$ are longitude and latitude, decimal degrees.

The humus content in the soils (table) corresponding to the quality grades of medium and higher contents $(>2.1 \%)$ characterizes $72 \%$ of the agricultural land area. The highest percent of the agricultural lands with medium and higher humus contents is characteristic of the cycled up-ground flow basin, which is $98.6 \%$ of the basin area, $68.4 \%$ of the river basin, and $60.3 \%$ of the coastal basin.

The maximum humus formation uniformity has been established for the soil of the cycled up-ground flow basin, which is confirmed by a slight variation $(1.7 \%)$ and a low value of the dispersion $(0.06)$. The river basin soils are characterized by the greatest humus distribution nonuniformity: variation is $3.54 \%$, excess is -0.47 , and the asymmetry evidences for the considerable nonuniformity of the minimum values. The humus content nonuniformity within the studied basins is largely dependent on soil type, anthropogenic load, and land use culture.

The forecasting reliability has been determined by dividing the time series in the ratio of 0.7 and 0.3 into two subsets: training (70\%, 26 years) and testing (30\%, 11 years). The reliability of the three-layer neuromodel based on a test sampling set in the stationary studies has reached $83-94 \%$, which evidences for the high reliability of the forecasted humus content for 11 years (until 2025).

The neuroforecasting results make it possible to conclude that the gradual dehumidification process is forecasted almost throughout the Kherson oblast until 2025 , if the existing agrotechnologies are used: by $0.01 \% /$ year in the rainfed land and by $0.03 \% /$ year in the irrigated land; the areas of the lands characterized by the medium and higher humus content will be reduced. The humus depletion is expected in the soils of the coastal basin and the southern part of the river basin, while a relatively stable situation is forecasted in the northern part of the river basin and the cycled upground flow basin. The reported approaches, methods, and results of the spatiotemporal modeling enable the comprehensive assessment of the agrochemical state and the utilization efficiency of the agricultural lands in the context of genetically different basins for the purpose of further development of works and implementation of the science-based project solutions to improve the utilization efficiency of natural basin resources in the steppe and dry steppe zones.

The investigation results can be used to justify the territorial priorities of the regional policy and to differentiate the soil-protective unit structure in the farming systems by its efficiency, while the developed method is universal enough to be used in other regions.

\section{REFERENCES}

1. Pichura, V.I., Spatial-temporal prediction of changes in parameters of agrochemical indices of reclaimed soils using GIS and neurotechnologies, Agrokhim. Gruntozn., 2012, no. 78, pp. 87-95.

2. Tyumentsev, N.F., Sushchnost' bonitirovki na genetikoproizvodstvennoi osnove (The Essence of Bonitation on Genetic-Production Basis), Novosibirsk, 1975.

3. Medvedev, V.V. and Plisko, I.V., Bonitirovka i kachestvennaya otsenka pakhotnykh zemel' Ukrainy (Bonitation and Qualitative Assessment of Arable Lands in Ukraine), Kharkov: Izd. "13 tipographiya," 2006.

4. Balyuk, S.A., Plisko, I.V., and Truskavets'kii, S.R., Efektivne vikoristannya gruntiv iz zastosuvannyam suchasnikh geoinformatsiinikh tekhnologii (Efficient Use of Soils Using Modern GIS Technology), Balyuk, S.A., Eds., Kiev: Agrarna nauka, 2011.

5. Bulygin, S.Yu., Achasov, A.B., and Lisetskii, F.N., Use of integral analysis of remote sensing data and digital 
terrain models for mapping the soil cover of the chernozem region, Nauchn. Ved. Belgorod. Gos. Univ., Ser. Estestv. Nauki, 2012, vol. 21, no. 21.

6. Neodnorodnost' pochv $i$ tochnoe zemledelie. Chast' 2. Rezul'taty issledovanii (Heterogeneity of Soils and Accurate Farming. Part 2. Results of Research), Medvedev, V.V, Ed., Kharkov: KP "Gorodskaya tipografiya," 2009.

7. Narozhnyaya, A.G. and Karpenskaya, S.Yu., The use of geoinformation technologies in the typification of basin structures, XXIV Plenarnoe soveshch. mezhvuz. nauchnokoordin. soveta po probleme erozionnykh, ruslovykh $i$ ust'evykh protsessov (XXIV Plenary Council of Interuniversity Scientific-Coordination Council on Problems of Erosion, Watercourse, and Estuary Processes), Barnaul, 2009, pp. 550-553.

8. Lisetskii, F.N. and Panin, A.G., The basin concept of nature management in rural areas of the Belgorod region, Vestn. Ross. Akad. S-kh. Nauk, 2013, no. 1, pp. $48-51$.

9. Haykin, S., Neural Networks: A Comprehensive Foundation, Prentice Hall, 1998, 2nd ed.

10. Pavlyuk, Ya.V., Terekhin, E.A., and Pichura, V.I., Use of neurotechnologies to simulate temporal processes of formation of river water content, in Erozionnye I ruslovye protsessy $i$ sovremennye metody ikh issledovaniya (Erosion and Watercourse Processes and Modern Methods of Their Research), Belgorod: LitKaraVan, 2014, pp. 141-148.

11. Lisetskii, F.N., Pavlyuk, Ya.V., Kirilenko, Zh.A., and Pichura, V.I., Basin organization of nature management for the solution of hydroecological problems, Russ. Meteorol. Gidrol., 2014, no. 8, pp. 66-76.

Translated by E. Maslennikova 